\title{
El mal: una respuesta desde la antropología de Torres Queiruga
}

\author{
CARlos AlBERTO VARGAS GONZÁLEZ* \\ Universidad de Medellín (Colombia) \\ cavargas@udem.edu.co
}

\begin{abstract}
Resumen
El problema del mal ha dado lugar a debates en diferentes ciencias durante toda la historia. La teología no ha sido exenta de esta problemática, sobre todo cuando trata de comprender cómo un Dios bueno y todopoderoso que crea por amor "consiente" el mal en su creación. Esta investigación tiene por objetivo responder al problema del mal, a través del pensamiento antropológico de Torres Queiruga, para lo cual se utiliza una metodología de tipo cualitativo-documental y un método interpretativo de toda la obra del teólogo español, arribando a la conclusión según la cual el mal es inevitable en la creación por su condición ontológica de finitud, por lo que la acción de Dios frente a este problema se da a través de las acciones amorosas del hombre, lo cual lo demostró Jesús de Nazaret, quien con su praxis existencial hizo evidente que Dios es el anti-mal.
\end{abstract}

Palabras clave: Antropología Teológica, creación, mal, ontología.

\section{Evil: a response from Torres Queiruga's anthropology}

\begin{abstract}
The problem of evil has given rise to debates in different sciences throughout history. Theology has not been exempt from this problem, especially when it tries to understand how a good and almighty God who creates by love "consents" the evil in his creation. This research aims to respond to the problem of evil, through the Torres Queiruga's anthropological thinking, for which a qualitative-documentary methodology and an interpretative method of the entire work of the Spanish theologian is used, reaching the conclusion according to the which evil is inevitable in creation because of its ontological condition of finitude, so that the action of God in this problem occurs through the loving actions of man, which was demonstrated by Jesus of Nazareth, who with his existential praxis It became clear that God is the anti-evil.
\end{abstract}

Key words: Theological Anthropology, creation, evil, ontology.

\footnotetext{
* Docente investigador del programa de Contaduría Pública de la Universidad de Medellín. Magíster en Administración (MBA), Teólogo y Contador Público. Tiene publicado el libro Hacia un Futuro de Grandes Encuentros: Razones para Fundamentar la Esperanza (2013); asimismo sus artículos “ ¿O Dios o el Mundo?: una respuesta a la disyuntiva camusiana desde el pensamiento teológico de Torres Queiruga" (2018); "Towards dialogic administration: a proposal from Gadamer's thinking" (2017); "Legado teológico del padre Alberto Ramírez en la Revista Cuestiones Teológicas” (2016).
} 
Muchas personas se hacen las siguientes preguntas: ¿si Dios es bueno por qué en el mundo se da el mal?, ¿vale la pena una creación así?, ¿será este mundo real el "mejor mundo posible"? Ahora, si el mundo es creado por Dios, ¿dónde está? Si él es un Dios amor y conocedor de las verdaderas necesidades humanas, ¿por qué no hace nada?, ¿dónde está la manifestación de sus dos grandes atributos de todopoderoso y bondadoso? En efecto, el mal percibido en la creación es una de las cuestiones existenciales más profundas que demanda una respuesta sin ambages para el sentido de la vida.

De allí que sea pertinente un acercamiento al problema del mal desde el ámbito de la antropología teológica, no como algo netamente religioso (cristiano), sino como una realidad humana, que cuestiona tanto a creyentes como a no creyentes o indiferentes, por lo cual resulta plausible sondear el problema mencionado, limitando el alcance al pensamiento de un autor gallego, Andrés Torres Queiruga, quien desde una fundamentación filosófica y teológica escruta el problema a través de toda su obra (Torres 2011; 2010; 2005a; 1999a; 1995a; 2005b; Cabada, 2013).

En consecuencia, esta investigación tiene por objetivo responder al problema del mal, a través del pensamiento antropológico de Torres Queiruga, para lo cual se utilizó una metodología de tipo cualitativo-documental, pues se hizo una revisión bibliográfica, cuyas fuentes primarias fueron las obras del teólogo español. El artículo, en primer lugar, muestra el antagonismo del mal con el Dios todopoderoso y bondadoso; en segundo lugar, ubica el mal como un problema ontológico desde la ponerología; y, por último, plantea la respuesta que da Dios al mal.

\section{El ANTAGONISMO DEL MAL CON EL DiOS TODOPODEROSO Y BONDA-} DOSO

Muchos aceptan, sin discutir, la proveniencia del mundo de Dios, pero en lo cual no hay consenso es en su intención amorosa a la hora de crear, pues la realidad parece demostrar lo contrario: un Dios amor, pero ausente; por eso, "la pregunta decisiva para el creyente no fue nunca: ¿Existe Dios?; sino ¿dónde está Dios?” (Torres, 1996a: 85).

Frente a tantas situaciones hostiles experimentadas en el mundo, Dios no sale muy bien librado, pues si se le adjudica el acto de la creación, necesariamente se le está haciendo responsable de todo el acaecer de esta. Entonces, aparece el condicionante al lado de la eterna pregunta que sacude las bases de toda justificación de Dios: Si Dios es bueno y todopoderoso, ¿por qué existe el mal? Es el famoso dilema de Epicuro: 
O Dios quiere quitar el mal del mundo, pero no puede; o puede, pero no lo quiere quitar; o no puede ni quiere; o puede y quiere. Si quiere y no puede, es impotente; si puede y no quiere, no nos ama; si no quiere ni puede, no es el Dios bueno y, además, es impotente; si puede y quiere — y esto es lo más seguro-, entonces ¿de dónde viene el mal real y por qué no lo elimina? (Epicuro citado en Torres, 1999b: 164)

Conciliar la bondad, el amor y el todo poder de Dios con el mal sucedido y padecido en la creación, ha resultado algo tan absurdo para muchos, hasta el punto de fundamentar en esto su ateísmo o indiferencia, porque es difícil comprender cómo un Dios con estos atributos permita o -en el peor de los casos- envíe situaciones tan atroces relacionadas con el mal físico y moral. Con relación a esta situación, algunos pensadores no conciben la idea de un Dios bueno y todopoderoso cuando contemplan, por ejemplo, el sufrimiento de los niños, tema que ha sido objeto de amplio debate en diferentes escenas de la literatura universal. Es así como Dostoyevski, por poner un caso, no logra comprender el padecimiento de los más pequeños e indefensos y la "aparente" indiferencia de Dios frente a ello:

Los padres de que te hablaba [le dice Iván a Aliocha] torturaban a su hijita de todas las maneras imaginables [...] Más tarde llegarán al supremo refinamiento de crueldad: haciendo un frío glacial, la encerraron durante toda la noche en un gabinetito excusado, bajo pretexto de que la pequeña no pedía que le llevaran a él cuando le era preciso hacer sus necesidades... Como si una niña de cinco años que está dormida como un ángel, pudiera pedir esas cosas en el momento apropiado... Para castigarla, le embadurnaron la cara con sus propios excrementos, y la forzaron a comérselos [...] ¿Puedes imaginar a aquel pequeño ser, que ni siquiera es capaz de comprender lo que ocurre, dándose golpes en el pecho, medio muerta de frío, en la oscuridad y en la pestilencia, derramando lágrimas inocentes y llamando en su ayuda a "su padrecito Dios" ¿Puedes comprender esto, amigo, hermano mío, humilde novicio que amas a Dios? ¿Eres capaz de entender por qué ha sido creado todo este absurdo? (Dostoyevski, 1974: 220-221)

Dostoyevski hace llegar a Iván Karamazov a la idea de la creación como un absurdo y a no creer en la armonía universal. Pero Iván, no contento con esto, le pregunta a su hermano Aliocha, el cual es creyente, lo siguiente:

-Contéstame con sinceridad, porque necesito tu parecer: imagínate que eres tú quien levantas el edificio de los destinos humanos, para lograr al fin hacer felices a los humanos, para lograr al fin hacer felices a los hombres, darles la paz, y la tranquilidad; pero para alcanzar esto te es indispensable torturar... 
tan sólo a un pequeño ser, a aquella niña que se daba golpes en el pecho, y fundar tu edificio sobre lágrimas no rescatadas. ¿Consentirías en ser el arquitecto en estas condiciones? ¡Contesta y dime la verdad!

-No, no consentiría en modo alguno -respondió suavemente Aliocha. (Dostoyevski, 1974: 225)

Esta pregunta formulada por uno de los Karamazov pone de manifiesto una verdad un tanto alarmante para la fe, y es la siguiente: el hombre tiene más buenas intenciones para con el hombre que el mismo Dios. De seguro la respuesta dada por Aliocha la darían casi todos los hombres, lo cual hace inferir a un Dios carente de bondad a la hora de crear. Por ello, muchos concluyen igual que Iván Karamazov: "No quiero esa armonía, no la quiero por amor a la Humanidad [...] Sí, demasiado precio [...], por eso me apresuro a devolver mi billete de entrada [...] No es que no admita a Dios, querido Aliocha. Tan sólo me contento con devolverle respetuosamente mi billete" (Dostoyevski, 1974: 225).

Comentando a Ivan Karamazov, Camus (1973a: 635) dice: "Si el mal es necesario para la creación divina, entonces esta creación es inaceptable". El autor francés también se resistía a comprender una creación donde los niños sufrían, de lo cual dan testimonio algunos apartes de su obra: "Estoy dispuesto a negarme hasta muerte a amar esta creación donde los niños son torturados" (Camus, 2001: 67). En este mismo sentido, en un diálogo con los dominicos, asegura que él seguirá "luchando contra este universo en que unos niños sufren y mueren” (Camus, 1973b: 359). Todo esto llevó al literato y filósofo argelino a concebir que quien se decide por la transformación del mundo necesariamente no debe aceptar a Dios, pues hacerlo sería dejar todo en manos del Creador cuando hay razones suficientes para creer que él está desentendido de su creación (Vargas, 2018).

Planteada la creación así, resulta un deber concebirla como la mejor prueba de la no existencia de Dios; o si existe, no le pertenecen aquellos atributos de los cuales tanta loa se le hace. Por ello Arthur Schopenhauer concluyó: "Si Dios ha hecho este mundo, yo ni quisiera ser Dios. La miseria del mundo me rompería el corazón" (1998: 83). Tal parece que Dios se tomó muy en serio el descanso del séptimo día y aún no ha podido despertar; aunque si duerme, como lo deja deducir Saramago (1999), tiene pesadillas de remordimiento, y de allí que su única excusa sea decir que no existe, como lo planteó Stendhal, a quien públicamente envidiaba el autor del Ecce Homo: “¿No estaré yo celoso de Stendhal? Me robó la mejor ocurrencia propia de un ateo, una frase que yo habría podido decir: 'La única excusa de Dios es decir que no existe"' (Nietzsche, 1982: 35). 


\section{HACIA UNA PONEROLOGÍA}

\subsection{Qué es la ponerología}

El término de ponerología, es propuesto por Andrés Torres (2010). Dicha palabra viene del griego panerós, cuyo significado es "malo", es decir, la ponerología sería el estudio de lo malo o del mal. Con esta categoría se pretende ubicar el problema del mal como un problema humano y no religioso. El autor lo plantea así: "De hecho, el mal atañe a las personas en cuanto humanas, prescindiendo de que sean religiosas o no" (Torres, 1999a: 23). En otra parte argumenta así:

El mal en la dura multiplicidad de sus diversas figuras atañe a las personas en cuanto bumanas, con independencia de que sean religiosas o irreligiosas. Está ahí desde que nacemos, afectándonos como daño que hacemos o que padecemos, como dolor físico u opresión social, como culpabilidad o desgracia, como catástrofe natural o crimen organizado... (Torres, 1999b: 188)

En este sentido, se trata de comprender el mal no desde Dios, sino como algo directamente relacionado con el hombre y el mundo como tal. Y esto tiene su razón de ser, porque el mal en sí mismo no depende de la fe de una persona en Dios, pues alguien incrédulo o indiferente debe enfrentarse igualmente con el padecimiento del sufrimiento en sus diferentes vertientes. De igual manera, quienes creen en Dios también les corresponde vivir las mismas experiencias del mal que a los ateos o indiferentes. El malentendido estriba en relacionar directamente el mal con Dios. La fe o la incredulidad son posturas frente al mal: "Las tomas de postura religiosas o irreligiosas son ya respuestas de distinto signo al idéntico interrogante que su terrible presencia nos plantea a todos" (Torres, 1999b: 188). En efecto, el mal concierne a todos y es un problema que se debe tratar de entender en el ámbito en el cual se da, esto es, en el humano.

\subsection{La inevitabilidad del mal en un mundo finito}

El mal se debe ubicar en el ámbito al cual realmente pertenece, o sea, en la constitución ontológica del mundo y del hombre, es decir, en el ámbito de lo finito. Sin necesidad de hacer mucho esfuerzo se demostraría cómo en lo finito existen límites. En consecuencia, dentro de lo finito se presentan carencias, ausencias, abandonos, insatisfacción, dolor, tristezas, angustias, etc. Sentado este presupuesto de la limitación se entiende o, por lo menos, se ubica en su debido puesto, el problema del mal. 
Ha sido en la limitación donde han encontrado la raíz al problema mencionado, y es Leibniz quien indicó las pautas para adentrar en la comprensión. Comentando al filósofo mencionado, Andrés Torres dice: "La limitación es la condición de posibilidad de todos los males, clasificados -con razón- en 'morales' y 'físicos', según que dependan o no de la libertad humana. Un mundo finito conlleva inevitablemente la existencia del mal" (1999a: 24). En otro texto, basándose igualmente en Leibniz, comenta:

Esta [la limitación] no es el mal [...], sino la condición de posibilidad que hace inevitable la aparición de los males concretos (los males reales, clasificados con razón en "físicos" o "morales", según dependan o no de la libertad). No se trata de que un mundo finito sea malo, sino de que no puede existir sin que en su funcionamiento y realización aparezca también el mal. [...] Y, desde luego, resulta muy difícil escapar a esta evidencia: una realidad finita y en realización es necesariamente carencial y está inevitablemente abierta al choque y a la competencia. En el mundo natural, unas cualidades excluyen a otras (si eres varón, no puedes ser mujer; si escoges una posibilidad, tienes que matar otra) y lo que uno acapara, demasiadas veces tiene que ser a costa del otro, a menudo hasta la tragedia. Tal sucede con la vida, que debe pagar su maravilla con la destrucción de otras vidas: mors tua vita mea, "tu muerte es mi vida". (Torres, 1999b: 190-191)

De las afirmaciones anteriores se pueden rescatar varios elementos. En primer lugar, al mundo le pertenece la contingencia, lo cual implica la limitación, y Torres Queiruga ve en esta limitación propiamente la condición que pone en el campo de las posibilidades el mal, de lo cual se desprende la imposibilidad de evitar dentro de lo finito la posibilidad del mal. No obstante, "esto no significa que la realidad sea mala en sí. Es 'buena', pero no de modo total y acabado. Lo que equivale a decir que es buena-afectada-por-el-mal, pues ha de irse realizando en lucha contra él, sin poder excluir nunca del todo el fracaso" (Torres, 1999a: 25).

Con lo anterior se puede subrayar cómo la finitud le pertenece al mundo y cómo es ella la condición para que el mal sea posible, sin afirmar con ello que la finitud en sí misma es mala. De la finitud se tiene una certeza evidente en la cotidianidad. Una decisión, por poner un ejemplo más, derroca otra posible a la hora de decidir. En esto se empieza a dejar entrever las tensiones traídas por la misma limitación del mundo, lo cual lanza a los hombres a verse continuamente privados de cientos de cosas y situaciones imposibles de darse al mismo tiempo con otras. Así, en la finitud se da el proceso, pues se experimenta un

carácter constitutivamente procesual de la finitud, el hecho de que "ser (finito) es tiempo"; tiempo como conatus essendi [esfuerzo por ser]: tomado, por un lado, 
en su mortal seriedad de realización en proceso siempre abierto y nunca asegurado y, por otro, en su gloria y dignidad de no deber rendirse nunca, empujando siempre un poco más allá los recios muros con que el mal tiende a cercarnos. (Torres, 1999b: 196)

En efecto, la finitud lleva ontológicamente inscrita una búsqueda demandadora de una realización o perfección cada vez mayor. Esto es más fácil de detectar en la humanidad, que tiene un impulso natural de querer ser más, es el deseo del cual el hombre nunca se ve totalmente librado en el mundo, es la "tragedia" existencial de la insatisfacción que a diario lo envuelve y lo lleva a vivir siempre en búsqueda, es una inquietud abrasadora, porque ontológicamente se sabe como un ser que pude ser cada vez más. Es la tensión puesta por la finitud como tal; el error está en atribuir esta tensión a Dios, esto no es algo mandado o permitido por él, es, más bien, el precio de la finitud: "Lo finito no puede ser perfecto. La finitud es siempre perfección a costa de otra perfección: 'perfección imperfecta' por definición" (Torres, 1986: 123).

Conviene ahora hacerse las siguientes preguntas: ¿por qué Dios creó un mundo limitado y contingente en el cual se da la posibilidad del mal, si él es infinito?, ¿cómo puede salir de alguien perfecto algo imperfecto? Pues bien, a la "hora" de crear -si se permite este contrasentido de tiempo-, Dios no podía crear algo perfecto, sería ilógico, pues "si Dios crea, no puede crearse así mismo: tiene que crear un mundo finito" (Torres, 1986: 130). Si Dios hubiera hecho un mundo perfecto habría creado dioses, algo absurdo.

Acá la ontología podría ayudar a esclarecer un poco lo absurdo de pretender que Dios "pudiera" crear algo perfecto. Al respecto puede dar una mano Parménides, quien hace un análisis sobre el Ser en su poema denominado "Sobre la Naturaleza" (Montero, 1960), cuyo eje central y principio fundamental es: "El Ser es y el No-ser no es" (V 2,3). Es preciso ver cómo la gran preocupación de Parménides es llegar a dilucidar el camino perfecto para llegar a la Verdad, por eso cuando llega donde la diosa ella le expresa tres vías: a) La de la Verdad: "Aquella que afirma que el Ser es y el No-ser no es" (V 2,3); b) La del error: "La que dice que el No-ser existe y que su existencia es necesaria" (V 2,5); c) La de la opinión: "Se ven llevados de aqui para allá, (los mortales) sordos, ciegos y llenos de asombro, como turba indecisa para la cual Ser y No-ser parecen algo idéntico y diferente" (V 6,6-8). Hecha esta aclaración, se puede mirar someramente cuáles son los atributos que Parménides descubre en el Ser por necesidad lógica: 
- El Ser es uno: se debe admitir la unicidad del Ser, porque afirmar la diversidad de "seres" son meras opiniones de los mortales, no es racional o, mejor dicho, se iría en contra del principio fundamental; pues si hay seres cada ser no sería lo que él no es, por ejemplo, la piedra sería piedra, pero no sería perro; por esta razón el Ser es necesariamente uno.

- El Ser es eterno: si se afirma que el Ser ha empezado a ser y dejará de ser, se diría inexorablemente que el Ser en un momento dado era Noser y que llegará, en un futuro, a No-ser; cosa absurda, porque el Ser nunca ha sido ni será No-ser: "No fue jamás ni será, ya que es abora en toda su integridad, uno y continuo" (V 8, 5-6).

- El Ser es continuo, homogéneo e indivisible: Parménides niega la división en el Ser, pues es todo igual por todas partes, no es ni más ni menos en ningún lugar ni momento, todo está lleno de Ser; pues como el Noser no es, es evidente su incapacidad para romper la continuidad del Ser. Su homogeneidad se fundamenta en su semejanza a "una esfera bien redonda" ( $\mathrm{v} 8,44)$; pues solo esta forma le permitirá mantener en equilibrio dinámico sus diversas posiciones; es este equilibrio el que le permite alcanzar uniformemente su totalidad: "Además, y dado que parece en último límite, el Ser está terminado por todas partes" (V 8, 43).

- El Ser es inmóvil: si el ser se trasladara o se moviera, forzosamente se reduciría a No-ser, pues la localización en diferentes espacios supondría la posibilidad de Ser y No-ser, porque en un lugar no sería lo mismo que en otro.

De estos atributos expuestos por el filósofo griego, interesa la relación del primero con el tema tratado de la imposibilidad de crear un mundo perfecto. El argumento es sencillo: si hubiera más Seres, en cada Ser existiría la posibilidad del No-ser, pues cada ser no sería lo que son los otros. En efecto, al hablar de Dios es absurdo pensar su obra de creación como algo perfecto, porque se estaría admitiendo todos los seres de la creación como dioses, en los cuales tendría que existir la unicidad del ser, pero al mismo tiempo se afirmaría un contrasentido, pues se admitiría que cada ser tendría un no ser (lo que él no es y son los demás seres).

Parménides habla de Ser en sentido absoluto, lo cual es analógicamente para la teología Dios. Así, cada ser -con minúscula- de la creación tiene el ser porque el Ser se lo ha dado, pero se lo ha dado en sentido finito, porque si Dios hubiera creado dioses hubiera creado su propio no ser. Se podrá objetar que Dios no es lo finito creado, pero se debe recordar la insistencia de Hegel según la cual Dios no se puede definir en oposición a lo finito, lo cual lo haría necesariamente finito, pues se pondría a depender 
de lo finito y, a su vez, se haría infinito lo finito al ponerlo en independencia de Dios. Dios incluye lo finito, sin ser ni agotarse en ello (Torres, 1987; 1995b; 1999c; Restrepo, 2015).

En efecto, de Parménides se aprende el atributo de la unicidad del Ser. Y esto, aplicándolo cuando se habla de Dios, muestra cómo él no podía crear un mundo perfecto sin hacer de este dios, algo absurdo en sentido ontológico, porque cada Ser estaría limitando a Dios y le estaría poniendo en el ámbito del no-ser:

Pensar en un mundo perfecto equivale a pensar en un "círculo-cuadrado" o en un "hierro-de-madera", y por la misma razón: sería postular una contradicción, un mundo finito-infinito. Dios "podría" no haber creado el mundo; pero si lo creó, este es finito; y, si es finito, en él no pueden no aparecer la carencia y la contradicción: el mal. De otro modo, o el mundo sería infinito como Dios o Dios tendría que estar cambiando continuamente las leyes naturales; para evitar las injusticias o los crímenes tendría que estar suspendiendo la libertad finita: para arreglar el mundo tendría que deshacer el mundo. (Torres, 2003: 261)

Por tanto, Dios se la jugó por un mundo finito. En terminología de Leibniz, "el mejor de los mundos posibles", pues no existía la posibilidad de un mundo perfecto. Por ello, Dios no "podía" crear un mundo sin mal, no por impotencia, sino porque eso sencillamente no era posible. Esto, evidentemente, no pone en entredicho la omnipotencia del Creador, sino que desvela la pretensión absurda poseída por el hombre de querer un mundo sin mal, "como diría Zubiri, no es que haya algo que Dios no puede hacer, sino que la posibilidad de ser criatura "no da más de sí"” (Torres, 1999a: 27). Se esclarece, por tanto, que un mundo infinito, es decir, en el cual no se den la posibilidad de mal de lo finito, es un absurdo, sería pedirle a Dios un imposible en sentido ontológico, y esto, lejos de poner al descubierto la impotencia de Dios, revela la inevitabilidad del mal en la finitud.

Todo esto desencadena en una consecuencia práctica para la fe, pues se pone de manifiesto lo carente de sentido que es hacerle "reclamos" a Dios por determinadas situaciones adversas que le suceden al ser humano relacionadas con el mal físico o moral (Torres, 1991a; 1996a). Si Dios estuviera interviniendo directamente, el mundo sería una marioneta, pues la libertad y las leyes, creadas por el mismo Dios, estarían siendo des-creadas por él. En efecto, es deshonesto para con Dios atribuirle el origen del mal, ya sea que con este pretenda poner a prueba o sacar un mayor bien. $\mathrm{Al}$ respecto, el teólogo gallego afirma lo siguiente: 
El mal no es algo que esté ahí porque Dios lo quiere, ni siquiera porque Dios lo permite. El mal está porque, siendo como es la realidad finita, no puede no estar; resulta desde todo punto inevitable [...]. Basta pensarlo un poco para ver que, de existir el mundo, el mal resulta inevitable; o, dicho de un modo un poco pedante, es metafísicamente insuprimible. Dios, si podemos hablar así, tenía la alternativa de crear el mundo o no crearlo. De crearlo, tendría que ser un mundo real: un mundo en el que hay que nacer y crecer, en el que hay que morir; donde, si estás en un sitio, no puedes estar en el otro; donde, si eres hombre, no puedes ser mujer; donde, si atiendes a uno, no puedes atender a otro... Lo cual, a nivel físico, comporta incompatibilidades y posibles catástrofes; a nivel biológico, sufrimientos y enfermedades; a nivel moral, posibilidad de injusticia, egoísmo y opresión. (Torres, 1991b: 21)

Dios tenía la posibilidad de no haber creado, pero decidió crear y si lo hizo él era consciente de la posibilidad del mal dentro de lo finito, sabía que el hombre le podía, desde su libertad, dar la espalda a su proyecto. Dios ha corrido el riesgo de la creación, lo cual debe conducir a la conclusión de que el mal no tiene la palabra definitiva: "Si Dios creó el mundo, es porque, a pesar de todo, el mundo vale la pena. [...] la negatividad del mal está envuelta en la positividad del mundo, que, en definitiva, resulta capaz de realizarse, que, de un modo o de otro, puede afirmar su sentido y defenderse contra el absurdo" (Torres, 1995c: 114).

\section{Dios Amor TODOPODEROSO ANTE EL MAL}

\subsection{Ubicación del atributo Todopoderoso en el ámbito ontológico}

Ha sido el autor de la primera carta de Juan quien ha dado una definición clásica y quizás poco comprendida acerca de Dios, pues lo identifica con el amor: "Dios es amor" (1 Jn 2,8.16). Esta expresión joánica muestra cómo el ser mismo de Dios consiste en amar. Ahora bien, para Torres Queiruga (1995c; 1996b; 2000; 2013) el amor es la razón por la cual Dios crea el mundo, lo que no es opacado por el mal, ubicado ya en el verdadero plano metafísico. Sin embargo, existe otra categoría que parece ser otro punto en donde se asen los ateos e incluso los mismos creyentes para "demostrar" a Dios como no amor: "Todopoderoso".

El "Todopoderoso" atribuido a Dios pone en una paradoja al ser humano cuando trata de conciliarlo con el Dios amor; ya el dilema de Epicuro, expuesto atrás, es una prueba de ello. ¿Cómo puede un Dios amor y Todopoderoso permitir, sea por cualquier intención, el sufrimiento de los que ama?, ¿qué padre bueno -y Dios es más bueno que cualquier padre 
(Lc 11,11-13) - si tuviera todo el poder, no ayudaría a erradicar los males padecidos por la humanidad?

En lo discutido hasta el momento ya se debe superar la siguiente tesis popular: Dios puede evitar el mal, pero no quiere. Esto deja un sabor de sadismo por parte del Creador, quien, por designios misteriosos de su voluntad, no hace nada para evitarlo. Por ello, muchos ponen el origen del mal en la voluntad de Dios, es decir, en su querer. No obstante, "si fuese posible mostrar que estas consecuencias no son necesarias, no habría dificultad en admitir que Dios 'no puede' evitar el mal, y a partir de ahí todo se haría más claro" (Torres, 2005b: 557-558).

El malentendido acá radica en la categoría "Todopoderoso". Sin lugar a duda, la mayor parte de las personas la entienden, cuando hace referencia a Dios, como un ser que todo lo que quiere lo puede hacer, incluso un absurdo, como lo es -expresión muy querida por el teólogo español- "un círculo cuadrado". Por lo antecedente, es preciso ubicar el concepto de "Todopoderoso" en el ámbito al cual realmente pertenece, es decir, al ontológico, de lo cual se desprende que Dios es Todopoderoso en su ser. Al respecto el pensamiento de Paul Tillich ilustra de la siguiente manera:

Si entendemos estas expresiones [Todopoderoso, omnipotencia divina] en sentido literal, Dios es entonces un ser, el mayor de todos, que puede hacer todo cuanto quiere, con lo cual se sobreentiende que existen multitud de cosas que Dios no quiere hacer, y este es un concepto absurdo, fruto de nuestra imaginación, que nos hunde en un total confusionismo. El significado real de la Omnipotencia es que Dios es el poder del ser en todo lo que es, trascendiendo infinitamente cada poder particular, pero actuando al mismo tiempo como su fondo creador [...]. Un poder que, en términos ontológicos, es la infinita resistencia contra el no-ser y la eterna victoria sobre él. (1970: 144-145)

El punto de partida de Tillich es el malentendido al cual ya se hacía referencia, y él, por su parte, hace énfasis en las consecuencias para con la imagen de Dios acarreadas al entender la omnipotencia de un modo errado. Es lo sucedido al judío "Yossel Rackover, [quien] hundido en el horror de la persecución nazi, se dirige a Dios con estas palabras: '¡Lo has hecho todo para que no crea en ti! [...] Creeré siempre en ti, a pesar de ti”" (Torres, 1999d: 215).

Los efectos en cuanto a la imagen de Dios de este modo de concebir el todo poder han sido bastante perniciosos. Es preciso aclarar que el atributo de "Todopoderoso" de Dios hace referencia a lo ontológico, como lo dice Tillich. De esta manera, ya no existe la indiferencia por parte de 
Dios, pues sería un absurdo ontológico pretender una acción directa por parte suya en el mundo finito.

Se puede concluir esta parte de la omnipotencia divina con unas expresiones de F.J. Tipler, comentadas por Torres Queiruga, quien presenta de una forma jocosa, pero acertada, lo absurdo de pretender proyectar en la omnipotencia divina el deseo irracional de querer un mundo sin mal:

"Si Dios es omnipotente, entonces Él podría hacer una piedra tan pesada que ni él mismo podría levantarla. Mas si ni siquiera Él puede levantarla, jentonces no es omnipotente!". A lo que responde con toda razón: "La omnipotencia de Dios no se encuentra limitada por la habilidad humana de decir tonterías. La omnipotencia de Dios solo quiere decir que Él puede realizar cualquier cosa que no sea lógicamente imposible" (F.J. Tipler). (Torres, 1999b: 206-207)

\subsection{Dios crea creadores}

De acuerdo con el pensamiento de Torres Queiruga, ha quedado dilucidado que Dios, dado su modo de ser, "no puede" intervenir en el mundo de una manera directa; adicional a ello, se ubicó el atributo de "Todopoderoso" en el ámbito ontológico. No obstante, todo esto conduce a la pregunta de cuál es la respuesta de Dios frente al mal, es decir, cómo actúa el Creador frente a la situación del mal.

El aporte bíblico empieza a ubicar el verdadero sentido de la acción de Dios en el mundo al mostrar al hombre como la imagen de Dios, y en esta línea, es el encargado de hacer sentir esa presencia divina de la cual el mismo Creador lo dotó, pues según el Génesis, Dios creó al hombre a su imagen y semejanza $(\mathrm{Gn} 1,26)$. La categoría "semejanza" salva la diferencia ontológica entre Dios y el hombre; en lo que respecta al "término célem ('imagen') significa de modo preponderante la plástica real, la copia y en ciertos casos el ídolo (1 Sam 6,5; Num 33,52; 2 Re 11,18; la pintura, en Ez 23,14), y sólo ocasionalmente la copia en el sentido minimizado de la apariencia respecto al original (Sal 39.7)" (Von Rad, 1977: 68). El mismo Von $\operatorname{Rad}(1977)$ recuerda que los reyes poderosos de la tierra hacían poner una estatua suya, como signo distintivo de su soberanía, en aquellos territorios que estaban bajo su mando y a los cuales ellos no podían asistir personalmente.

En efecto, la misión del ser humano es hacer viva y real la acción (la imagen) del Creador en el mundo. Dios, para actuar en la tierra, "depende" del hombre. Ya Tomás de Aquino lo expresaba así: "La providencia de Dios es el hombre" (Citado por González-Carvajal, 1989: 124). Esto se comprende si se aclara que la acción de Dios es trascendente, y, por lo tanto, 
esta solo se hace visible a través de la acción de la criatura, la cual es inmanente, lo que viene a significar que no tiene su razón de ser en sí misma, sino en la trascendente: "La acción de Dios es trascendente, y eso significa que sólo se hace visible y efectiva a través de la acción creada, la cual es inmanente y sólo resulta posible apoyada en aquélla" (Torres, 1999d: 288). En otra parte, el autor muestra la interdependencia del hombre y del Creador:

Dios actúa en la misma acción de la criatura, y ésta actúa sostenida por la acción divina, la cual es de orden trascendente y sólo toma cuerpo empírico y categoría en cuanto actuando a través de aquella, que a su vez sólo existe en cuanto apoyada en la divina: actuamos porque Dios actúa (orden trascendente); y Dios actúa de manera eficaz en el mundo porque actuamos nosotros (orden categorial). (Torres, 1996a: 114-115)

Es evidente la interrelación de "dependencia" que el autor trata de mostrar entre Dios y el hombre: ambos se "necesitan". En este punto, podría ayudar una mirada rápida sobre el texto del Génesis, concretamente al comienzo del capítulo segundo: acá se expone el día séptimo de la creación, en el cual hay algo muy bien intencionado por parte del autor, pues falta la fórmula conclusiva, esto es, "atardeció y amaneció..." común en todos los seis antecedentes días. Con San Agustín se puede decir que aún se está en el día séptimo de la creación, es decir, Dios sigue creando hoy: aún no se ha concluido el día séptimo (Von Rad, 1977). Pero se percibe algo de igual relevancia: en el día sexto Dios había creado al hombre, y después de haberle dado su misión de señorío sobre la creación, Dios "descansa" -sin dejar de crear, pues la creación está siendo sida siempre por Dios- y el actuar, desde ese momento, le compete propiamente al hombre, el cual a su vez es la imagen de Dios, y en este sentido, es el mismo Dios quien actúa a través de su máxima obra de la creación.

Andrés Torres se apoya, para justificar la acción de Dios a través de las criaturas, en una máxima de Henri Bergson: "Dios crea creadores". Con dicha expresión se salva la autonomía tanto de la acción de Dios como la del hombre. Los dos actúan sin suplantarse el uno al otro, pues cuando el hombre actúa es verdaderamente él quien lo hace, pero Dios es quien continuamente lo está haciendo ser y, en esta línea, es Dios quien actúa. En este sentido, la acción de Dios en el mundo consiste en hacer que las criaturas hagan:

Así, respecto de las criaturas Dios no hace algo al lado de ellas, para completarlas, ni en lugar de ellas, para suplirlas. Justamente, porque es creador, la acción de Dios en las criaturas es hacer que ellas hagan, ya que, al crearlas, Dios 
les da, junto al ser, la capacidad de obrar. Ello nada resta a su obrar de criaturas: este ser y esta capacidad de obrar les son entregadas realmente, de modo que son ellas las que "hacen" sus acciones, las cuales son verdaderamente suyas.

Podemos decir lo mismo invirtiendo la consideración: la acción es de la criatura porque Dios la está haciendo ser y obrar y, en este sentido, la acción es también "de Dios". He ahí, por qué la acción de Dios se da en el plano trascendental: porque Dios "hace hacer", y "hace" de verdad en el hacer de la criatura. Así se comprende que cuanto más "hace" Dios, tanto más "hacen" las criaturas, y viceversa: cuanto más "hacen" las criaturas, tanto más "hace" Dios [...] Todo lo hace Dios y todo lo hace la criatura. (Torres, 1999e: 288)

En esta misma línea se da la argumentación del autor de El Principio esperanza cuando asegura que para Dios ser tal el hombre debe ser verdaderamente hombre: "Sed vosotros hombres y Dios será Dios" (Bloch, 1968: 85). Así, utilizando la terminología de Boff (2007) para quien algo es sacramental cuando a través suyo se hace transparente lo trascendente, se puede sostener que la misión del ser bumano es transparentar en la inmanencia la acción trascendente de Dios por medio de sus actos, los cuales solo resultan posibles en cuanto están apoyados en la iniciativa divina de querer ayudar siempre y a todos. San Pablo lo expresa así: "A aquel que tiene poder para realizar todas las cosas incomparablemente mejor de lo que podemos pedir o pensar, conforme al poder que actúa en nosotros" (Ef 3,20); en otra parte dice: "Pues Dios es quien obra en vosotros el querer y el obrar, como bien le parece" (Flp 3,6). El autor de estas cartas enseña la iniciativa de Dios, quien tiene poder para hacer todo mejor de lo que se pueda pedir, y lo hace conforme al poder actuante en el hombre, esto es, a través de la acción de este, pero es Dios quien obra en el ser humano el querer y el obrar.

En efecto, no hay ausencia de Dios, solo existe ausencia del hombre quien no se arriesga a amar. Si el ser humano tomara conciencia de la vocación de ser imagen de Dios, se comprometería realmente en la transformación del mundo en lugar de estar con las manos cruzadas, o arrodillado suplicando la intervención de Dios. Bonhoeffer (1969: 25) lo expresa así: "Creo que Dios puede y quiere que el bien nazca de todo, incluso de lo más malo. Para ello necesita unos hombres por quienes todas las cosas concurran al bien". Es ineludible, sin la disposición de la libertad humana, Dios no "puede" hacer real su misericordia en el sufrimiento. Torres lo resume de la siguiente manera: "Dios entra en la historia y transforma el mundo no a base de milagros e intervencionismos, sino a través de su presencia reveladora en la libertad del hombre" (1987: 235). 
Con estos argumentos podría salir al camino de la reflexión esta pregunta: ¿hasta dónde actúa el hombre y hasta dónde actúa Dios?, o planteada de otra manera, ¿cómo conciliar la gracia de Dios y la libertad humana? Parece que la acción de Dios, para ser efectiva, debe suplantar la libertad humana anulándola; o bien, parece ser que, si la libertad es real, entonces no existe acción propiamente de Dios. Este punto ha sido uno de los grandes debates a lo largo de la historia teológica, pues la gracia parece excluir la libertad, y viceversa. Pero ya la respuesta a este dilema, sin ser enunciado expresamente, está aclarada: Dios crea creadores, y en este sentido, "la acción de Dios se realiza en y a través de la libertad humana por ella sustentada; el ejercicio auténtico de esa libertad es el lugar privilegiado en el que se transparenta Dios como fuente de energía que suscita y como polo de amor que trae" (Torres, 1987: 188).

\subsection{Jesús como la respuesta vivida de Dios ante el mal}

Jesús es el punto de encuentro entre Dios y el hombre: "el Dios para el hombre y el hombre para Dios" (Torres, 1996c: 2). En él callan los argumentos y habla una praxis concreta, la cual sacia plenamente al Creador y al hombre. El Creador le preguntaba al hombre, después de la caída de Adán: "Hombre, ¿dónde estás?" (Gn 3,9); el hombre le recriminaba a su Hacedor la ausencia: “Dios mío, Dios mío, ¿por qué me has abandonado?!” (Sal 22,2). En Jesús ambos callan, porque el nazareno responde con obras concretas. Le responde a Dios: "Entonces yo dije: Aquí estoy, oh Dios para hacer tu voluntad" (Hb 10,7). Le responde al hombre: "Yo estaré con vosotros todos los días hasta el final de los tiempos" (Mt 28,20). Es decir, Jesús hace una justificación de Dios (teodicea) frente al hombre, y viceversa, esto es, una justificación del hombre (antropodicea) frente a Dios. La teología cristiana tiene en la mano la apología para justificar a Dios y al hombre, y dicha apología es la persona de Jesús de Nazaret.

Ya se veía que el mal parece quitar todo argumento cuando se quiere hablar y hacer "razonable" a Dios. Pues bien, ¿qué hacer frente al mal?, ¿cómo argumentar la bondad de Dios con este problema? La mejor respuesta de Dios frente al mal es la persona histórica de Jesús de Nazaret; él, con su vida, sus palabras y sus obras demostró cuál es la actitud existencial frente a los inconvenientes de la vida. Dice Torres al respecto: "Tanto sus palabras [las de Jesús] como, sobre todo, sus obras son una continua proclamación de Dios como el anti-mal; como el que llega a la humanidad para romper el dominio absoluto de todas las fuerzas que la esclavizan y atormentan" (1986: 135).

En los signos del reino (milagros) realizados por Jesús de Nazaret, Dios apuesta todo por luchar contra el mal. Jesús fue el Anti-mal, él no se 
preguntaba por la "ausencia de Dios", sino que hacía efectiva la presencia divina a través de su persona; Jesús no se preguntaba por la causa del mal, sino que luchaba contra él; Jesús no se preguntaba la razón por la cual el Padre, Todopoderoso y Bondadoso, no actuaba, sino que él actuaba en nombre de Dios y hacía transparente el poder y la bondad del Creador. Por ello, Jesús es el caso logrado de la creación, él hizo posible el proyecto que tenía Dios desde Adán, fue quien llegó a la edad adulta, descubriendo la divinidad de todo hombre. Varone lo expresa así: "En Jesús Dios realizó la Imagen, el Icono perfecto de su gloria. Primogénito de una multitud de hermanos $([\mathrm{Rm}] \mathrm{8}, 29)$-primogénito no en sentido numérico o histórico, sino ontológico-" (1988: 225). Jesús llegó al para de la creación, en él toda la obra creadora alcanzó su máxima realización. En este sentido, Jesús no fue la víctima querida por el Dios caprichoso para aplacar su ira, sino Aquel que alcanzó la meta proyectada por el Creador al formar al hombre.

Es en este sentido, y solo en este, como Jesús salva (Torres, 1995c; 1995d; 1996d). Jesús no salva de la ira de Dios, sino que descubre el camino para llegar a ser realmente hombres, es decir, para llegar a ser aquello para lo cual ha sido creada la humanidad. No es que Dios haya empezado a salvar en sentido cronológico a partir de Jesús, él ha estado salvando desde el momento mismo de la creación, lo sucedido es que hasta Jesús no había sido descubierto. El hombre no tiene que hacerse valer ante Dios por los méritos de Jesús, su papel es aceptar el camino inaugurado por Jesús, es decir, el camino de la salvación presente desde siempre como opción de vida para todos los humanos.

Por todo lo anterior es que hay esperanza a pesar del mal (Torres, 2005a; 2005c; 2005d; 2005e). El cristianismo le apuesta a la vida porque la sabe sustentada, apoyada y animada por la fuerza siempre presente y activa del Creador. Definitivamente vivir vale la pena porque Cristo lo demostró: "Merece la pena ser hombre, pues Dios quiso ser uno de ellos" (Boff, 1985: 65), es decir, el mismo Dios en carne quiso mostrar cómo la vida tiene sentido cuando se vive como "imagen y semejanza" suya, es decir, teniendo como referente al Creador y como misión la de hacer transparente la acción suya en el mundo: "Él mismo (Dios) se hizo uno de nosotros, a fin de realizar en nuestra carne nuestro mismo proyecto finito; no colocándose fuera del cerco doloroso del mal, pero sí traspasándolo con la fuerza salvadora del amor infinito" (Torres, 1995c: 137). Dios, en la persona de Jesús, hizo palpable que la vida vale la pena de ser vivida cuando frente al sufrimiento no se permanece como un sujeto pasivo, sino cuando se lucha, sin ahorrar energías, contra él, tratando de hacer un mundo más justo y humano, es decir, más divino. Por ello, se puede ver en la Navidad la clave de muchos misterios frente a los cuales el hombre puede abdicar: 
La Navidad nos proporciona la clave para descifrar algunos profundos misterios de nuestra existencia. Los hombres se preguntaban angustiados el porqué del dolor, el porqué de la humillación, el porqué de la pequeñez sentida y padecida. Los hombres le preguntaban a Dios. Y Dios guardaba silencio. Los hombres buscaban argumentos para eximir a Dios de los desórdenes de la historia. Pero ninguna respuesta podía silenciar las preguntas que nacían de las raíces del corazón dolorido. Ahora, en la Navidad habla Dios. Y el hombre queda en silencio, ya no pregunta más. Se limita a escuchar la narración del acontecimiento de la dulzura Divina y humana: Dios nació pequeño; Dios se hizo historia, Dios se apellida pesebre. Dios no responde al porqué del sufrimiento, sino que co-sufre. Dios no responde al porqué del dolor, sino que se hace varón de dolores. Dios no responde al porqué de la humillación, sino que él mismo se humilla. Ya no estamos solos, Él está con nosotros. Ya no somos solitarios, sino solidarios. Ha enmudecido la argumentación de la razón y comienza a hablar la narración del corazón. Se narra la historia de un Dios que se hace criatura, que no pregunta, sino que hace, que no responde, sino que vive una respuesta. (Boff, 1985: 63-64)

Dios responde al mal en Jesús, quien, viviendo una respuesta en su persona, ha tomado una postura con respecto a aquello que parece arrebatarle al hombre el sentido de la existencia; en Jesús, Dios afirma que vale la pena vivir: "Si Él (Dios) se decidió a hacer la tremenda apuesta de nuestra existencia, fue porque en su Hijo estaba dispuesto a jugarse entero por nosotros" (Torres, 1995c: 222). En Jesús habla Dios de una manera elocuente y actúa de una manera irrebatible contra el mal. Son las obras de los seguidores de Jesús las que deben mostrar la victoria del bien sobre el mal, enseñando que este será envuelto y vencido por el amor becho carne (Torres, 1996e; 1983).

En Jesús Dios está totalmente opuesto al mal y experimenta a su Abbá como aquel que solo quiere el bien para el hombre y como el primer opuesto a todo lo malo; pero esta experiencia no es abstracta, no es algo basado exclusivamente en éxtasis, la cual no tiene influencia en el compromiso personal; al contrario, es una experiencia que se hace carne, es decir, se hace real en la praxis existencial. Jesús reconoció en Dios la bondad, el amor y el poder; pero esto, lejos de volverlo un sujeto pasivo esperando todo de la providencia divina, lo hizo adquirir conciencia de una misión específica: mostrar la bondad, el amor y el poder del Creador a través de sus manos: Jesús se hizo providencia de Dios.

\section{CONCLUSIÓN}

El mal es una realidad evidente y es imposible negarlo (Bernstein, 2002). Es flagrante, mas las respuestas parar tratar de comprenderlo suelen 
ser escurridizas. Su realidad no solo reta el intelecto, sino que se convierte en una pregunta existencial que puede conducir al absurdo y, consecuentemente, a la no aceptación de Dios (Camus, 1973c), por lo cual no está fuera de lugar preguntarse si, a pesar del mal, Dios sigue siendo un ser confiable (Stackhouse, 2009).

Lo que sí es cierto respecto al mal es que es una cuestión que ha inquietado al ser humano a través de toda la historia, y por ello ha buscado respuestas a este fenómeno desde diferentes perspectivas. Es así como ha dado respuestas mitológicas, teológicas y filosóficas (Ricoeur \& Pellauer, 1985). No obstante, sigue habiendo un enorme abismo entre la visibilidad del mal y la escasez de los argumentos intelectuales para hacerle frente (Bernstein, 2002). La pregunta de por qué se da el mal sigue abierta por ser algo que toca las fibras más profundas de la existencia humana.

Sin embargo, al ser una cuestión abierta da lugar a que se den respuestas desde diferentes cosmovisiones. Es así como aparecen respuestas que sostienen que más adelante, gracias al avance tecnológico, el ser humano será capaz de crear mundos artificiales, lo cual disminuiría sustancialmente la pregunta por el mal natural (Crummett, 2020; Dainton, 2020). Asimismo, siguen vigentes los argumentos clásicos que giran en torno a que Dios permite el mal para bienes mayores, pero que no tiene la intención del mal (Mooney, 2019).

Por lo anterior, el mal se convierte en un reto para los creyentes (Collins, 2019; Law, 2010), para la teología (Koistinen, 2017; Ricoeur \& Pellauer, 1985; Torres, 2001) y para la filosofía (Neiman, 2002; Ricoeur \& Pellauer, 1985). Más específicamente, desde el punto de vista teológico, el mal es el primer interrogante que sale al camino de la antropología, sobre todo en lo relacionado con la teología de la creación (De la Peña, 1996), al ser "una de las preguntas más acuciantes y que más difícil hacen mostrar la credibilidad del Dios cristiano" (Silva, 2009), de allí el gran reto que supone este fenómeno para le reflexión sobre Dios (Gesché, 2010). No se puede dudar de la buena fe de las respuestas teológicas y "populares", pero lo que sí se puede cuestionar son las consecuencias perniciosas con la imagen del Dios revelado por Jesús de Nazaret que en múltiples ocasiones dejan estas respuestas.

Por ello, Andrés Torres, consciente de esta situación, ubica el mal en un plano ontológico, es decir, mostrando que en un mundo necesariamente creado con un modo de ser finito es inevitable la realidad del mal físico y moral. En efecto, es menester interpretar el mal en el sentido metafísico de la criatura, esto es, el mal se da como consecuencia de la finitud natural, denominada mal físico, dentro del cual se pueden enumerar los males de la naturaleza propiamente dichos: las enfermedades, los desastres y el deterioro normal de la naturaleza. Pero también se da como efecto de 
la finitud libre y del poder (Vargas, 2010), conocido como el mal moral, fruto de las decisiones humanas: violencia y guerra en general. Ahora bien, el mal en términos generales es "comprensible" dentro de la creación y no contradice la intención amorosa de Dios a la hora de crear, sino que es el riesgo asumido por el Creador para compartir la felicidad suya con sus criaturas.

La "apuesta" de Dios en la creación está "motivada" por "la esperanza" suya en el Hombre. En definitiva, la creación estaba orientada a la encarnación (Sayes, 2002), pues fue un hombre, Jesús de Nazaret, quien comprendió plenamente el proyecto que Dios tenía en la creación. Por ello, el Nazareno entendió su vivir divino en tanto que humano, y se comprometió radicalmente a luchar contra el mal con sus palabras y, sobre todo, con sus acciones. Este camino trazado por Jesús es el proyecto del cristianismo, dado que sus seguidores deben vivir como vivió él: "Quien dice que permanece en él, debe vivir como vivió él” (1 Jn 2,6). En efecto, la respuesta de Dios al mal sigue dándose cada vez que hay un acto humano que lucha por hacer un mundo más humano y, consecuentemente, más divino.

En este sentido, lo que sí es claro en el cristianismo, de acuerdo con la argumentación de Torres Queiruga, es que la actitud frente a la inevitabilidad del mal no es el letargo de una esperanza en el más allá mal entendida, ni tampoco es dejar todo en las manos de Dios, sino que es un llamado para vivir un compromiso radical con la transformación del mundo a través de acciones que hagan más real la imagen de Dios (Vargas, 2018).

Ahora bien, no puede perderse de vista que la respuesta cristiana al problema del mal es una posición hermenéutica, es decir, la interpretación de una realidad inevitable desde una perspectiva del reinado de Dios. En el fondo, el mal es un problema que no se soluciona, porque es parte constitutiva de la creación por el hecho de ser ontológicamente finita. Sin embargo, sí se puede interpretar a la luz de la praxis concreta de Jesús de Nazaret, quien tuvo la intuición de que el ser humano, más que respuestas teóricas, lo que necesita son acciones concretas cuando es abrasado por el mal.

Lo anterior se evidencia en el evangelio cuando el Nazareno sentía compasión por las personas que padecían el mal en diferentes formas (Mt 14,14; Mc 6,34; Lc 7,13), término que es mucho más profundo en el idioma original del evangelio, pues "el verbo griego esplaginizomai, usado en todos estos textos, se deriva del sustantivo esplaginon, que significa vientre, intestinos, entrañas, corazón, es decir, las partes internas de donde parece surgir las emociones profundas. El verbo griego, por consiguiente, indica un movimiento o impulso que fluye de las propias entrañas, una reacción visceral" (Nolan, 1981: 50). No en vano Jesús es considerado "el 
poeta de la compasión” (Pagola, 2010: 117). Desde el latín, por su parte, misericordia, es el concepto que recoge esta experiencia -del latín miser (miserable o desdichado) y cor, cordis (corazón)-, que significa dar el corazón al mísero. En Jesús, por tanto, se evidencia que "el nombre de Dios es misericordia" (Francisco, 2016).

En consecuencia, uno de los retos que le queda a la teología del futuro es, sin lugar a duda, ser narrativa (Mardones, 1988) como lo era la "teología” de Jesús. De este reto no está exenta la presentación del problema del mal, pues el hombre contemporáneo -o posmoderno- ya no resiste los grandes relatos ni las divagaciones abstractas que se complacen en sí mismas desde el punto de vista lógico, pero que no tienen incidencia directa en el desarrollo cotidiano de la existencia (Ramírez, Vargas \& González, 2013). Por tanto, el desafío que le presenta el mal a la teología no gira tanto en hacer una "justificación de Dios" (teodicea), sino en hallar las maneras de cómo hablar de él a pesar de la inevitabilidad y evidencia del mal (Hernández, 2018).

En efecto, el problema del mal debe ser presentado de una manera narrativa, así como lo hizo Jesús, que no acudió a elucubraciones abstractas, sino que de una manera pedagógica tomaba los elementos cotidianos de sus conciudadanos y contaba experiencias, como da testimonio la manera de narrar el reinado de Dios a través de las parábolas (Meier, 2017). Esto no significa que se deba renunciar a la profundidad de los argumentos; al contrario, es un desafío para que la presentación del problema del mal no pierda su agudeza y, sobre todo, para que sea fecunda en el presente y futuro del ser humano. Por ello, parafraseando al filósofo español Ortega y Gasset (2004: 9), se puede decir que la claridad ha de ser la cortesía del teólogo al presentar el problema del mal.

Como muestra de una teología profunda y narrativa, se puede concluir con un bello himno litúrgico de la hora sexta, el cual pone de manifiesto, de una manera poética y con una intuición teológica profunda, la presencia de Dios en su creación, de ese Dios que sigue trabajando a través del hombre:

Te está cantando el martillo y rueda en tu honor la rueda. Puede que la luz no pueda librar del humo su brillo. ¡Qué sudoroso y sencillo te pones a mediodía, Dios de esta dura porfía de estar sin pausa creando, y verte necesitando 
del hombre más cada día!

Quien diga que Dios ha muerto

que salga a la luz y vea

si el mundo es o no tarea

de un Dios que sigue despierto.

Ya no es tu sitio el desierto

ni en la montaña se esconde;

decid, si pregunta dónde,

que Dios está - sin mortaja-

en donde un hombre trabaja

y un corazón le responde. Amén

\section{REFERENCIAS}

Bernstein, R. (2002). Radical Evil: A Philosophical Interrogation. Cambridge: Polity Press.

Boff, L. (1985). Encarnación: La humanidady la jovialidad de nuestro Dios. Santander: Sal Terrae.

Boff, L (2007). Los sacramentos de la vida y la vida de los sacramentos. Bogotá: Indo American Press Service Ltda.

Bloch, E. (1968). Thomas Munzer, teólogo de la revolución. Madrid: Ciencia Nueva.

Bonhoeffer, D. (1969). Resistencia y sumisión. Cartas y apuntes desde el cautiverio. Barcelona: Ariel.

Cabada, M. (2013). Infinitud y problema del mal. En diálogo con A. Torres Queiruga. Estudios Eclesiásticos. Revista de investigación e información teológica y canónica, 88(344), 143-173.

Camus, A. (1973a). El hombre rebelde. En Obras Completas. (Tomo II). México: Aguilar.

Camus, A. (1973b). Actualidades I. En Obras Completas. (Tomo II). México: Aguilar.

Camus, A. (1973c). El mito de Sísifo. En Obras Completas. (Tomo II). México: Aguilar.

Camus, A. (2001). La peste. Bogotá: Unión Ltda.

Collins, J. M. (2019). The evil-god challenge: extended and defended. Religious Studies, 55(1), 85-109.

Crummett, D. (2020). The real advantages of the simulation solution to the problem of natural evil. Religious Studies, 1-16.

Dainton, B. (2020). Natural evil: the simulation solution. Religious Studies, 56(2), 209-230.

De la Peña, J. (1996). Teología de la creación. Santander: Sal Terrae.

Dostoyevski, F. (1974). Los hermanos Karamazov. Barcelona: Buguera.

Francisco. (2016). El nombre de Dios es misericordia. Una conversación con Andrea Tornielli. Santiago: Planeta.

Gesché, A. (2010). El mal (Dios para pensar, I). Salamanca: Sígueme. 
González-Carvajal, L. (1989). Esta es nuestra fe. Teología para universitarios. Santander: Sal Terrae.

Hernández, H. (2018). La teodicea, el pathos de Dios y el Crucificado en la teología de la cruz de Jürgen Moltmann: una lectura contemporánea. Veritas, (40), 121-144.

Koistinen, T. (2017). The problem of evil and the grammar of God. Neue Zeitschrift für Systematische Theologie und Religionsphilosophie, 59(3), 394-409.

Law, S. (2010). The evil-god challenge. Religious Studies, 46(3), 353-373.

Mardones, J. (1988). Posmodernidad y cristianismo. El desafio del fragmento. Santander: Sal Terrae.

Meier, J. P. (2017). Un judio marginal. Nueva visión del Jesús histórico V: La autenticidad de las parábolas a examen. Estella: Verbo Divino.

Montero, F. (1960). Parménides. Madrid: Gredos.

Mooney, J. (2019). Divine intentions and the problem of evil. Religious Studies, 55(2), 215-234.

Neiman, S. (2002). Evil in Modern Thought: An Alternative History of Philosophy. Princeton: Princeton University Press.

Nietzsche, F. (1982). Ecce Homo. Bogotá: Skla.

Nolan, A. (1981). ¿Quién es este hombre? Jesús Antes del cristianismo. Santader: Sal Terrae.

Ortega y Gasset, J. (2004). Qué es la filosofía - Unas lecciones de metafísica. México: Porrúa.

Pagola, J. (2010). Jesús. Aproximación histórica. Buenos Aires: Ed. Claretiana.

Ramírez, A., Vargas, C., \& González, J. (2013). Hacia un futuro de grandes encuentros. Razones para fundamentar la esperanza. Medellín: UPB.

Restrepo, L. Revelación y teología de las religiones: J Dupuis y A. Torres Queiruga en diálogo. Theologica Xaveriana, 22(180), 447-470.

Ricoeur, P., \& Pellauer, D. (1985). Evil, a challenge to philosophy and theology. Journal of the American Academy of Religion, 53(4), 635-648.

Saramago, J. (1999). El Evangelio según Jesucristo. México: Alfaguara.

Sayés, J. (2002). Teología de la creación. Madrid: Palabra.

Schopenhauer, A. (1998). El amor, las mujeres y la muerte. Medellín: Cometa de papel.

Silva, S. (2009). La Teología de la Liberación. Teología y vida, 50(1-2), 93-116

Stackhouse Jr, J. (2009). Can God be trusted?: faith and the challenge of evil. Illions: InterVarsity Press.

Torres, A. (1983). ¿Qué significa creer en el Dios de Jesús en nuestra sociedad burguesa? Iglesia Viva, (107), 489-514.

Torres, A. (1986). Creo en Dios Padre. El Dios de Jesús como afirmación plena del hombre. Santander: Sal Terrae.

Torres, A. (1987). La Revelación de Dios en la realización del hombre. Madrid: Cristiandad.

Torres, A. (1991a). Más allá de la oración de petición. Iglesia Viva, (152), 157-193.

Torres, A. (1991b). El Dios de Jesús. Aproximación en cuatro metáforas. Santander: Sal Terrae. 
Torres, A. (1995a). El mal inevitable: replanteamiento de la teodicea. Iglesia Viva, (175-176), 37-70.

Torres, A. (1995b). Qué significa afirmar que Dios habla. Selecciones de Teología, 34(134), 102-108.

Torres, A. (1995c). Recuperar la salvación. Por una interpretación liberadora de la experiencia cristiana. Santander: Sal Terrae.

Torres, A. (1995d). ¿Qué queremos decir cuando decimos infierno? Santander: Sal Terrae.

Torres, A. (1996a). Recuperar la Creación. Por una religión bumanizadora. Santander: Sal Terrae.

Torres, A. (1996b). La idea de creación: radicación filosófica y fecundidad teológica. Iglesia viva, (183), 211-234.

Torres, A. (1996c). Repensar la cristología. Sondeos hacia un nuevo paradigma. Estella: Verbo Divino.

Torres, A. (1996d). Cuando decimos infierno, ¿qué queremos decir? Selecciones de Teología, 35(139), 197-211.

Torres, A. (1996e). Responsabilidad de los cristianos en el mundo actual. Cristianismo y sociedad, (128), 33-37.

Torres, A. (1999a). Mal y omnipotencia. Del fantasma abstracto al compromiso del amor. Selecciones de Teología, 38(149), 18-28.

Torres, A. (1999b). Del terror de Isaac al Abbá de Jesús. Hacia una nueva imagen de Dios. Estella: Verbo Divino.

Torres, A. (1999c). La experiencia de Dios, posibilidad, estructura. Pensamiento, 55(211), 35-69.

Torres, A. (1999d). ¿Somos los últimos cristianos... premodernos? Selecciones de teología, 38(151), 214-218.

Torres, A. (1999e). Recuperar, con los jóvenes, el camino de Dios. Selecciones de Teología, 38(152), 283-289.

Torres, A. (2000). Fin del cristianismo premoderno. Retos hacia un nuevo horizonte. Santander: Sal Terrae.

Torres, A. (2001). Ponerología y Resurrectión: El mal entre la filosofía y la teología. Revista Portuguesa de Filosofia, (57), 539-574.

Torres, A. (2003). Repensar la resurrección. La diferencia cristiana en la continuidad de las religiones y de la cultura. Madrid: Trotta.

Torres, A. (2005a). La realización concreta de la esperanza: el mal desde la cruz y la resurrección. Theologica Xaveriana, (154), 267-292

Torres, A. (2005b). Mal. En J. Tamayo (Ed.), Nuevo diccionario de Teología (pp. $555-$ 562). Madrid: Trotta.

Torres, A. (2005c). La estructura fundamental de la esperanza bíblica. Theologica Xaveriana, (154), 227-252.

Torres, A. (2005d). Elpidología: la esperanza como existenciario humano. Theologica Xaveriana, (154), 165-183.

Torres, A. (2005e). Esperanza a pesar del mal. La resurrección como horizonte. Maliaño: Sal Terrae.

Torres, A. (2010). De la 'Ponerología' a la teodicea: el mal en la cultura secular. Boletín Staurós, (49), 5-12. 
Torres, A. (2011). Repensar el mal. De la ponerología a la tedoicea. Madrid: Trotta.

Torres, A. (2013). Creados por amor. La santidad cristiana. Concilium, (351), 345364.

Tillich. (1970). Amor, poder y justicia. Análisis ontológicos y aplicaciones éticas. Barcelona: Ariel, S.A.

Vargas, C. (2018). ¿O Dios o el mundo?: una respuesta a la disyuntiva camusiana desde el pensamiento teológico de Torres Queiruga. Cuestiones Teológicas, 45(103), 127-148.

Vargas, J. (2010). El mal como posibilidad de la libertad y el poder según Hans Urs von Balthasar. Veritas, (22), 161-189.

Varone, F. (1988). El Dios sádico. ¿Ama Dios el sufrimiento? Santander: Sal Terrae.

Von Rad, G. (1977). El libro del Génesis. Salamanca: Sígueme. 